\title{
DIE KULTUURKRISIS EN
}

DIE VERBONDSJEUG

\section{Die rewolusie van die eensames.}

Elke dag van die week, van die maand, van die jaar wend in Johannesburg gemiddeld twee persone ' $n$ poging aan om selfmoord te pleeg') - om in die dood hierdie lewe te ontvlug, skynbaar sonder gedagte aan die "weeropstanding van die vlees, en ' $n$ lewe in eewge duurte, as die dood nie meer sal wees."

Psigiaters getuig dat die meeste van hierdie selfmoordpogings aangewend word deur jongmense. En opvallend is die rede wat byna sonder uitsondering aangegee word vir hierdie droewige laaste ontvlugtingspoging: Dit is ' $n$ wanhoopspoging om te ontvlug aan ' $n$ radelose, reddelose, drukkende, ondefinieerbare eensaamheid wat hom dikwels manifesteer in 'n skynhare grond-lose angs.

Berigte van die eensame worsteling van miljoene eensame jongmense met hierdie ondefinieerhare eensaamheid hereik ons uit alle dele van die wêreld. Uit Amerika en Kanada word herig dat die eensaamheid soms so drukkend word dat selfs jong getroude paartjies dit in mekaar se gesel. skap nie meer kan uithou nie en dan uitvlug, deur die drukkende eensaamheid uitgedrywe word na plekke van wilde vermaak en ontspanning om in die bedwelming van dronkenskap en verdowingsmiddels of in

1) Onderhoofartikel The Star van 3 Feb. 1956. die wilde oerwoudritme van die jazzband ontvlugting te soek. ${ }^{2}$ ) Miljoene mense oor die hele wêreld stroom saans, smiddae, en ook al soggens na die hioskoopsale om in die vervoering van die onwerklike opwindende rolprentverhaal, al is dit net vir ' $n$ paar uur, die knaende eensaamheid te ontvlug.

Van al hierdie ontvlugtingspogings is indiwiduele selfmoord egter nog nie die ontstellendste nie. Die angswekkendste is dat miljoene mense, ja, die ganse mensdom van die twintigste eeu onbewus besig is om heskawingsmoord te pleeg - om die bykans tweeduisend jaar oue, en grootste van alle beskawings, die Westerse christendomlike kultuur en beskawing te vernietig.

In sy aangrypende werk met die veel. seggende titel van Revolutie der eenzamen toon dr. P. J. Bouman ${ }^{3}$ ) vir ons asof in 'n spieël hoe die eensaamheid van enkelinge en van miljoene gedurende die twintigste eeu ineegewerk het tot die ontstaan en die afloop van reeds twee wêreldoorloë binne ' $n$ enkele mensegeslag.

2) Talryke koerantberigte getuig o.a. hiervan. Let ook veral op die talryke brlewe van „eensames" in die korrespondensie kolomme van veral ons Engelse koerante in Suid-Afrika.

3) BOUMAN, DR. P. J.: Revolutie der eenzamen, Van Gorcum en Comp., Assen, MCMLV, Nederland. 
In 'n ander verband ") maak dr. Bouman, soos ook ander skrywers, weer melding van drie geslagte. Daar is die ou geslag wat nog maatstawwe uit die tydperk van voor 1914 aanlê, hulle leef nog by prinsipes; hulle is nog "inner-directed"; hulle word gerig deur 'n innerlike kompas. Hulle speel nog 'n groot rol in die boonste verdwynende laag van die nasionale godsdienstig-kulturele lewe. Hulle imponeer deur die sekerheid van hulle oordeel, ook wanneer daardie oordeel skynbaar onrealisties is. Die middelgeslag het volwassenes geword tussen die twee wêreldoorloë. Hier. die middelgeslag laat hulle lei deur hulle realisme, hulle wetenskaplike en tegniese deskundigheid. Hulle het ideale gekoester van sosiaal-ekonomiese herstel en opbou terwyl die lewenskode wat hulle persoonlike lewens gerig het net nog tot 'n mate aangesluit het by die ou geslag. Die jong geslag is diegene wat sedert 1945 volwasse geword het. Daar is dié radikale verskil tussen laasgenoemde geslag en die vorige twee geslagte $\mathrm{nl}$. dat die jong geslag totaal gebreek het met die lewenskode wat nog as tradisie die lewens van die vorige twee geslagte beheers het. Die jong geslag wil "vry" bly van en het dus gebreek met alle bindinge van ,ideologiese" aard.

Uit die voorgaande is dit af te lei dat daar 'n ,ideologiese", 'n godsdienstig-kulturele breuk plaasgevind het; 'n gaping ontstaan het tussen die jong geslag, d.w.s.

4) Vergelyk sy artikel ,Maatschappelijke Achtergrond" in die Aug./Sept. 1955 uitgawe van die maandblad Wending; Maandblad vir Evangelie en Kultuur, Boekencentrum, 's Gravenhage, Nederland. die moderne jeug en die ouere geslagte.

Hierdie breuk dui die keerpunt aan in die christendomlike Westerse kultuur en beskawing. Sommige kenners van ons tyd ${ }^{5}$ gaan so ver as om die jaar 1955 as die spesifieke datum van die keerpunt in die Westerse kultuur en heskawing aan te dui. Persoonlik meen ek dat die swaartepunt in sommige opsigte reeds vroeër al verskuif het.

Of dit nou al moontlik is om bo alle twyfel 'n hepaalde jaar as die keerpunt in die Westerse kultuur aan te dui of nie een feit moet in die oë gestaar word, en dit is dat ' $n$ nuwe wêreld hesig is om in ons midde op te staan - 'n wêreld wat oor veertig of vyftig jaar vorentoe oorheer. send geregeer en belewe sal word deur die huidige jong geslag - die moderne jeug, die eensames wat nie terugdeins vir rewolusionêre dade nie, wat die eie lewe gering ag, wat ' $n$ ander visie het op die ou bely. denis van die "weeropstanding van die vlees, en ' $n$ lewe in eewge duurte, as die dood nie meer sal wees".

Hierdie waarheid maak in wese die kultuurkrisis uit.

\section{Die kultuurkrisis.}

\section{Die krisis.}

„Kultuur” kan vir die doeleindes van hierdie artikel omskrywe word as 'n positiewe (bouende en versorgende) wyse van lewensindiensstelling deur enkelinge, huisgesinne, groepe, volkere ens., selfs oor verspreide wêrelddele (bv. die Jode), ooreen-

5) Byvoorbeeld POLAK, PROF. DR. FRED $\mathrm{L}$, in sy werk De toekomst is verleden tijd; De Haan, Utrecht, MCMIV. 
komstig een of ander bepaalde lewenskode as tradisie, en met 'n daarmee ooreenstem. mende bepaalde toekomsverwagting.

So was die christendomlike Westerse kultuur vir bykans tweeduisend jaar ten diepste beheers deur die Christelike lewens. kode as tradisie met die geloofsoog gerig op die komende Godsryk. Alles het gestaan onder die mandaat van die eerste, tweede en derde bede: „... laat U Naam geheilig word, laat $U$ koninkryk kom, laat $U$ wil geskied....". Die lewensindiensstelling van die Rooms-Katolieke en die ortodokskatoliek het geskied ooreenkomstig hierdie lewenskode opdat hy die koninkryk mag beërwe; die lewensindiensstelling van die Protestant omdat hy die koninkryk mag beërwe.

Rondom hierdie sentrale gedagte het die christendomlike Westerse kultuurpatroon homself ontplooi ooreenkomstig die wet van God, wat op die alledaagse lewe van toepassing was. By hierdie grondtema het in die kultuurpatroon alle elkedaagse handel en wandel 'n hetekenis verkry. Oortreding van die kultuurpatroon was sonde, was skuld voor Cod, want vir die christen. gelowige is daar die allernouste verband tussen kultus en kultuur. ${ }^{6}$ )

Die Joodse geleerde Polak vind die

6) Vgl. KUYPER, A.: Encyclopaedie der heilige godgeleerdheid, 2e hersiene druk; Kok, Kampen, 1909, bl. 513-514; en SCHILDER, PROF. DR. K.: Christus en cultuur, Wever, Franeker; asook VENTER, C. N.: Professionele maatskaplike werk en sy verhouding tot pastorale werk; ongepubl. M.Soc.Sc.-verhandeling, P.U. vir C.H.O., o.a. pag. 35-37. wese van die christendomlike Westerse kultuur in sy eschatologiese uitgangspunt. Eschatologie omskryf hy dan ${ }^{7}$ ) as daardie vorm van theodicee wat die historiese ge beure as heilsgebeure sien afrol volgens ' $n$ voorbestemde, noodwendig te verwesenlike „,plan der Voorzienigheid" tussen die skepping as oerbegin en die verlossing as voleinding, d.w.s. die wonderbare herskepping deur God van hierdie wêreld, ná die oordeel op die jongste dag, tot 'n gans ander wêreld... die ewige koninkryk van God.

Vir doeleindes van hierdie artikel kan ons hierdie definisie van Polak, met enkele voorbehoude, aanvaar omdat ons graag wil kom tot dit wat hy as die teenhanger van eschatologie sien, nl. utopie. Utopie wil die geskiedenis onderwerp aan planne wat deur mense ontwerp is, en nie langer "aan een plan, vasgesteld van Hoger Hand". Utopie stel menslike mag teenoor bo-menslike mag, dit rig homself op die aarde en nie op die hemel nie, is dus inmanent en nie transen. dent nie. Die utopie rig die blik na die verhouding tot die medemens en het geen oog vir die verhouding tot God nie. Kortom die utopie is 'n planmatig gekonstrueerde en met die voortgaande historiese ontwikkeling gesinkroniseerde toekoms. heeld van '" gans ander, regverdige en menswaardige samelewing, welke ideaal, deur die, ter wille van die vooruitgang in die tyd en op die aarde, verantwoordelike mens, vryskeppend en doelbewus en to cie lotsbepaling kan en moet benader word.

7) POLAK, PROF. DR. FRED L.: a.w. deel I, pag. 319 e.v. 
Vanuit Calvinistiese standpunt gesien is dit duidelik dat eschatologie en utopie soos hierbo geskets mekaar uitsluit - me. kaar se doodsvyande is.

In sy diepste wese bestaan die kultuur. krisis, vanweë die toenemende ontkerstening van die Westerse mensdom, in 'n felle botsing wat tydens en tussen die afgelope twee wêreldoorloë sy hoogtepunt bereik het, tussen die christelik-eschatologiese kultuurpatroon en die antichristelikutopistiese kultuurpatroon, waarin laasgenoemde skynbaar die oorwinning behaal het, met die gevolg dat ons tans 'n ontwrig. tende, onsekere, onstabiele en beklemmende oorgangstydperk belewe.

In die Ooste vind dieselfde botsing tussen die tradisionele Oosterse kultuurpatrone en die nuwe utopistiese kultuurpatroon plans, met die gevolg dat in die Ooste oënskynlik dieselfde oorgangsimptome waargeneem kan word.

Altesame stuur die Weste en die Ooste albei af op één wêreldomspannende náchristendomlike utopistiese kultuurpatroon met Die Mens op die troon. Die mens wat met sy wetenskap en sy tegniek sy eie heil sal uitwerk; deur sosiaal-ekonomiese „planning", ofte wel maatskaplike enginieurskursus, sy eie verlossing sal bewerk.

\section{Dieper grond van die krisis.}

Die nodige perspektief ontbreek nog op hierdie nuwe kultuurpatroon van die wêreld. Ons staan nog te veel aan die be. gin van sy ontplooiing en die mensdom is nog te vecl ontwrig en losgeslaan, te verward en onseker - tydens hierdie oorgangstydperk -- hy kan nog nie bewustelik volgens die lyne van die nuwe kultuur. patroon sy lewe in diens stel nie - hy eksisteer voorlopig nog net.
Al wat ons voorlopig van die nuwe kultuurpatroon gewaar word is o.a. dat die moderne wysbegeerte besig is om afstand te doen van alle wysheid en begeerte na die hoëre en ons probeer onderdompel in 'n worsteling met die dood en ás die dood nie meer sal wees nie, die Niks, dat die moderne kuns ons ö̈ en ore soos optiese en akoestiese instrumente wil rig op die onskone, die afgryslike en die chaotiese; dat die diepte-psigologie trag om die mens met sy sondige natuur te versoen en dit tot norm te verhef; dat die wetenskap en tegniek die mens oënskynlik vorm tot 'n slaafse wese met die opdruk massaal, meganies en materialisties. Maar die ontstellendste is dat die religie sy transendente karakter verloor en hoe langer hoe meer toegee aan die druk van die „Social Science" wat in alliansie met die weten. skaplike utopisme of scientisme aan die ganse mensdom 'n nuwe religie gee - die religie van die kommunard.') Hieraan help die moderne teologie eerder mee as om dit te bestry.

In die religie van die kommunard word die menslike gemeenskap of broerskap of maatskap of kameraadskap of kommune of mede-menslikheid tot afgod verhef en bewus of onbewus ywerig gedien, want die utopis het slegs oog vir die verhouding tussen mens en medemens. Een derde van die mensdoin het agter die ystergordyn reeds hierdie godsdiens, soos in die Kommunisme vergestalt, bewustelik aanvaar.

8) Ek neem voorlopig dié term, met sekere voorbehoude, oor uit die werk van SCHILDER, DR. K.: De openbaring van Johannes en het sociale leven; Meinema, Delft, 1951, bl. 16. 
Duskant die ystergordyn dien die mensdom reeds dieselfde afgod en beoefen hulle ook reeds die religie van die kommunard - maar hulle is daar nog nie bewus van nie. Hulle spreek wel reeds van die verantwoordelikheid van die gemeenskap of die maatskappy, wat d.m.v. gemeenskapsorgane soos maatskaplike organisasies, maatskaplike werkers, die totalitêre welsynstaat, ens. as verteenwoordigers van die gemeenskap (of maatskappy) moet voorsien in al die stoflike en geestelike node en behoeftes van die lede van die maatskappy of gemeenskap - van die wieg tot aan die graf... en daarna: NIKS.

Eintlik skyn dit só te wees dat Europa en die Anglo-Amerikaanse wêreld voorkeur gee aan die terme maatskappy of gemeenskap (,society" en „community”); die Oosterling het hierdie terme as tegniese terme oorgeneem, hoewel hulle meer gevoel het vir die term „broerskap”. Dieselfde geld vir die Slawiese wêreld, waar die term „kameraadskap" egter weer sterk op die voorgrond tree. Oor die algemeen egter het hierdie terme in hierdie verband min of meer sinoniem geword - hulle gevoelswaarde is in hierdie verband dieselfde en hulle dui almal oor die algemeen vandag op: die religie van die kommunard. By ons is die terme maatskappy en gemeenskap, of ook die voorvoegsel „sosiaal-" algemeen in gebruik. Baie persone gebruik nog hierdie terme los en vas son. der dat hulle die hedendaagse draagwydte daarvan begryp.

Die hunkering na gemeenskap is 'n fundamenteel menslike sielsbehoefte - by die eschatologis sowel as by die utopis. By die gelowige word hierdie behoefte, soos deur die Skepper bedoel, bevredig in die gemeenskap met God deur Christus, wat ook die gemeenskap met die broeders en susters van dieselfde hemelse Vader meebring. Hierdie enigste ware gemeenskap tref ons aan in die universele kerk, die liggaam van Christus. In hierdie gemeenskap van die heiliges ervaar die ge. lowige die troosvolle werking van die Heilige Gees en hier is geen blywende, beang. stigende en knaende eensaamheid denk. baar nie. Hier word die gemeenskapsdrang op meta-sosiale wyse bevredig.

By die onwedergebore en onbekeerde heiden, klassiek sowel as by die moderne utopis, is hierdie meta-sosiale bevrediging van die natuurlike hunkering na gemeenskap afwesig, want die heiden is van nature geneig om God en sy naaste te haat. $\mathrm{Hy}$ ervaar nié die vertroosting deur die Heilige Gees nie. Hierdie tweespalt in sy onwedergehore hart, nl. 'n natuurlike hunkering na gemeenskap asook 'n natuurlike neiging om sy Skepper na wie se beeld hy geskape is te haat, bring ' $n$ ontsettende vereensaming en beangstiging in sy siel mee.

Dan soek hy na troos in 'n skyngemeen. skap met sy medemens, wat hy egter ook van nature haat. Gemeenskap word by hom bewus of onbewus 'n obsessie, dit waarvan sy geluk en gemoedsrus en sy voortbestaan afhanklik is. Gemeenskap met sy medemens word by die moderne utopis sy afgod, en sosiale aanpassing die sleutcl tot daardie gemeenskap. Só ontstaan die religie van die kommunard, wat alle grense tussen indiwidue, groepe, klasse, volke en rasse wil uitwis, $\left.{ }^{9}\right)$ om sodoende die nuwe ná-

9) Vgl. hier die insiggewende werk van NISBET, ROBERT A.: The quest for community; Oxford University Press, New York, 1953. 
christendomlike utopistiese kultuurpatroon daar te stel.

Hierdie hunkering na gemeenskap kan egter nooit werklik op sekulêre en profane wyse, deur middel van sosiale aanpassing, bevredig word nie - dit leer reeds Daniel 2 : 43 ons: „Hulle sal deur menslike gemeenskap onder mekaar vermeng raak, maar hulle sal nie aan mekaar vasklewe nie, net soos yster nie met klei meng nie".

Daarom kan die utopistiese toekomsverwagting nooit werklik werklikheid word nie; daarom bly die oorloë - warm en koud; daarom bly die beangstigende eensaamheid met as skynbare laaste uitvlug die individuele selfmoord, want daarna is daar mos - NIKS.

\section{Gevolge vir die verbondsjeug.}

As daar spesifiek oor die jeug gehandel word moet daar duidelik onderskeid gemaak word tussen die jeug in die algemeen en die verbondsjeug in die besonder. Die kultuurkrisis tref die verbondsjeug besonder hewig, want in ons moderne "neutrale" staatskole, waar almal volgens dieselfde patroon gevorm word, word ook die verhondsjeug in die nuwe ná-christendomlike utopistiese kultuurpatroon ingelyf om daarná in dieselfde gesekulariseerde „maatskappy" uitgestoot te word, om deur dieselfde winde van lering heen en weer gewaai te word en deur dieselfde tydgees heinvloed en meegesleur te word - tensy hulle besonderlik en afsonderlik vir hulle dienswerk, d.i. hulle kultuurtaak of hulle amp as gelowige ${ }^{10}$ ) toegerus word (vgl. Ef. 4 : 11-16).

Tot hierdie besef, nl. dat die verbondsjeug vir hulle kultuurtaak in hierdie nachristendomlike wêreld afsonderlik toege- rus moet word, het die moderne christendom nog nie ontwaak nie - omdat hulle eintlik nog onbewus is van die kultuurkrisis, van die feit dat die wêreld anders geword het, dat 'n nuwe kultuurpatroon besig is om vorm aan te neem en die bykans tweeduisendjaar oue christendomlike kultuurpatroon vinnig te vervang. Die moderne jeug leef reeds, hoewel duskant die ystergordyn meestal nog onbewus, by die nuwe antichristelike kultuurpatroon.

Met sy mond en sy hart bely die gelo. wige jongeling wel nog die christelike geloof, maar daar vind daagliks 'n ontsetten. de worsteling in sy siel plaas omdat hierdie belydenis nie strook met die kultuurpatroon waarby hy van kleinsaf ingelyf word nie. Dit bring spanning, verwarring en radeloosheid mee, wat dikwels dan in sinkretisme 'n skynoplossing vind.

In die verwarring en radeloosheid wat meegebring word deur die spanning tussen twee botsende wêrelde, twee stelle lewenskodes, twee kultuurpatrone, word ook die verbondsjeug kopsku soos steeks perde, apaties, afsydig - wil hulle aan niks openlik deelneem nie. Hierdie klag hoor ons in alle Westerse lande: die jeug ken nie meer die geesdrif en idealisme wat vroeëre jeugbewegings gekenmerk het nie, hulle wil hulle nie meer laat bepropageer nie. Slefs die verbondsjeug wil aan die kerk. like jeugverenigings nie meer meedoen nie.

Hierdie lewenshouding van die jeug het die verdere gevolg dat ook die verbondsjeug terugsink in 'n nuwe soort indiwidualisme. Hulle bly alleen tuis - wat in die groot stede beteken in hulle losies-

10) Vgl. voetnoot 6) hierbo. 
kamers waar hulle spoedig die eensaamheid voel druk. Prinsipieel behoort die verbondskind die eensaamheid nie te vrees nie. Dit is die tyd vir selfondersoek, vir meditasie, vir gebed, vir gemeenskap met God. Prinsipieel behoort die eensaamheid op die verbondskind net die teenoorgestelde uitwerking te hê as op die ongelowiges, onbekeerdes, en ontkerstendes.

As die verbondsjeug egter nie vir hulle dienswerk goed en voortdurend toegerus word nie (vgl. Ef. 4 : 11-16) hou hulle, want hulle is sondige mense, in die eensaamheid ook maar hulle gedagtes besig met die materiële, met die stoflike, die aardse - met die hier en nou - ook van hulle eie individuele liggaamlike drange en drifte - dan word ook die stryd teen die duiwel, die wêreld en die eie vlees vir hulle te magtig.

Die duiwel, die wêreld en die eie vlees vind hier 'n magtige bondgenoot in een van die "evangelies" van die nuwe kultuur - nl. die diepte-psigologie, wat in elke koerant en tydskrif "raad gee" of ,geestesgesondheid bevorder". Dit sou dan sleg wees vir die gesondheid om jou drange en drifte te onderdruk en jouself te beheer - jou te steur aan objektiewe etiese norme. Die norme dra jy in jouself, jou eie geluk en genot bepaal in hierdie harde wêreld wat vir jou goed is.

So keer dan ook die moderne verbondsjongeling in tot homself, so draai sy lewe en sy wêreld naderhand ook net om sy eie selfsugtige self. Hier het 'n nuwe vorm van een van die grondgedagtes van die humanisme, nl. dat die mens die maatstaf van alle dinge is, hom in sy strikke gevang.

Immers, dit gaan hier nie meer om die mens as verteenwoordiger van die alge- meen menslike nie, maar dit gaan hier om die indiwidualiteit in sy eie gevarieerde struktuur-samehang, wat die reg het om sy eie "so-wees" op 'n eie eiewyse wyse, en in eie verband uit te lewe, solank as andere nie daardeur belemmer word om weer hulle eie "so-wees" op eie wyse en in eie verband uit te leef nie. Elkeen kamp op sy beurt teen dit wat vir homself nadelig is, sonder dat aan daardie nadelige (of voordelige) 'n objektiewe etiese kwalifikasie gegee mag word.") Hierdie nuwe individuealisme bring sy besondere probleme mee vir ,gemeenskapsvorming": By die verbondsjongeling is dit 'n sterk faktor wat bekering bemoeilik, terwyl dit by die wêreldling volgens die eise van die nuwe kultuur die "aanpassing" by die „maatskappy" of die "gemeenskap" belem. mer.

In noue verbinding met hierdie individualisme staan die faktor waarop reeds eerder gewys is, nl. dat die jeugdige hom slegs besig hou met die hier en die nou. $\mathrm{Hy}$ het geen eschatologiese toekomsverwagting nie - die uiteinde van alles is presies: Niks. Hy wil aan niks uit die verlede en in die (onsekere) toekoms gebind wees nie. $\mathrm{Hy}$ is die oombliksmens wat van oomblik tot oomblik leef. Daar is geen kontinue lewenssin nie. Slegs die voordeel of genot van die oomblik het waarde.

Hierdie kenmerk van die moderne jeug laat sommige skrywers dink aan die hoer uit Openbaring. Sy leef immers van moment tot moment - by die genot van die

11) WATERINK, J., e.в.: Cultuurgeschiedenis van het Christendom; Elsevier, Amsterdam-Brussel, 1951, deel V, bl. 356-357. 
oomblik. As sy haar gewas het dan vergeet sy wat gebeur het.

Hierdie eise wat die nuwe kultuurpatroon aan die jeug stel lewer besonder groot probleme op. Dit verblind die vermoë van die verbondsjeug om die Verbond as sodanig, sowel as die komende Godsryk, voortdurend as 'n (metafisiese) werklikheid te sien en te beleef, terwyl sy ganse lewensuitkyk deur die tydgees van die hier en die nou gevorm en meegesleur word.

Ten slotte is dit noodsaaklik om daar. op te let dat die kultuurkrisis in wese eintlik net die verbondsjeug ernstig in gedrang bring. Die wêreldlinge is eintlik gepredestineer om die nuwe kultuurpatroon te aanvaar en hulle lewens daardeur te laat rig. Hulle kan eintlik nooit effektief en intensief genoeg daarby "aanpas" nie.

$o_{p}$ die verbondsjeug egter rus die verantwoordelikheid om met die genade van God die christelike lewenskode dwarsdeur die kultuurkrisis en selfs die ryk van die Antichris heen te dra tot die voleinding toe - tot God alles sal wees en in almal.

Vir hierdie dienswerk, hierdie kultuurtaak moet die verbondsjeug in hierdie krisistyd afsonderlik en anders toegcrus word as die wêreldlinge, omdat daar aan hulle in die Raadsplan van God, in soverre dit in Sy Woord aan ons geopenbaar is, ánder eise gestel word as aan die wêreld. linge. Ten opsigte van die verbondsjeug is die eis van die tyd dus nié "aanpassing" nie maar reformasie en bekering.

Miskien is dit "Nog nie die einde nie".'1) Miskien is 'n diepingrypende reformasie, vanuit die wortel, nog moontlik soos vantevore al gebeur het. Die christelike lewenskode verplig ons tot reformasie, want dit mag miskien nog eeue duur voor die werklike koms van die Antichris.

Laat ons daarom reformeer en nie by die nuwe kultuurpatroon aanpas nie.

\section{Calvinistiese jeugsorg.}

In die voorgaande gedeelte is getrag om 'n uiteensetting te gee van die wyse waarop die kultuurkrisis die verbondsjeug tref. Dit mag wees dat die meeste Calviniste die voorgaande gedeeltes nog in mindere of meerdere mate kan onderskryf. Wanneer ons egter daartoe moet oorgaan om die probleme op praktiese wyse, mens. likerwys gesproke, die hoof te bied, sal die weë uitmekaar begin gaan. Verskillende metodes van "sorg”, „voorsorg" en „nasorg" sal aan die hand gedoen word, en die voor- en nadele van elke ander metode of vorm van „sorg" sal teen mekaar opgeweeg word. Die een sal 'n voorstander van hierdie metode wees en die ander 'n voorstander van daardie metode.

Wat is nou eintlik ons maatstaf as ons die voor- en die nadele van een of ander metode of vorm van sorg teen mekaar hegin opweeg? Sou elke metode dalk sy maatstaf of norm vir goed of kwaad in homself omdra? Word ons nie dan prag. matisties of opportunisties nie?

Of, sou nóg 'n beter manier van tewerkgaan nie wees om alle metodes te ondersoek en dan die heste uit elke me-

12) Nog nie die einde nie is die titel van 'n werk deur dr. P. J. Meyer, uitgewers A. A. Balkema, Kaapstad-Amsterdam, 1954. Ek haal hier egter net die titel van die werk aan sonder om noodwendig dr. Meyer se gevolgtrekkinge te onderskryf. 
tode te neem en also supermetodes van sorg, voorsorg of nasorg saam te stel nie?

Die vakwetenskap Maatskaplike Sorg, wat hom besig hou met die bestudering van die verskillende, soms botsende, metodes van sorg, leer aan ons dat elke bepaalde metode met sy verskillende tegnieke ook sy eie onderliggende grondbeginsels en filosofie het, wat gesien en verstaan moet word in samehang met die geestesstrominge waarvan hulle, d.w.s. die verskillende metodes van sorg, op bepaalde tye en onder bepaalde omstandighede die historiese kultuurprodukte is.

Te alle tye het die geesstrominge wat die mensdom beheers het óók die houding bepaal wat die verskillende samelewingsgroepe respektiewelik ingeneem het teenoor sekere verskynsels in die samelewing. So verskillend dus as wat in die loop van die eeue die geestesstrominge was, só verskillend was te alle tye die vorme en metodes van sorg, voorsorg of na-sorg wat in verskillende menslike samelewingsgroepe aangewend was. Elke vorm of metode van sorg kan dus gesien word as 'n uitkristallisering van 'n bepaalde lewens- en wêreldheskouing, ideologie of leerstelling. ${ }^{(3)}$ )

Ter verduideliking kan daarop gewys word hoedat selfs binne die Christendom, by bv. Rooms-Katolieke, Lutherane en Calviniste, verskillende metodes van sorg aangetref word omdat die leerstellinge of dogmas waarop daardie metodes gefundeer is van mekaar verskil.

Soveel te meer moet hierdie warheid geld vir die huidige botsing tussen die

13) Vgl. o.a. EVERTS EN TREURNIET: Gids voor Maatschappelijke Werk; Samson, Alphen aan den Rijn, 1954, bl. 25. christendomlike en na-christendomlike antichristelike kultuurpatrone.

Laasgenoemde het ons egter só onver. hoeds oorval en só goed skuilgegaan agter die sogenaamde „neutraliteit" van die wetenskap en die tegniek, ook die sosiale wetenskappe en sosiale tegnieke, dat Calviniste vandag sonder enige voorbehoud moderne heidense metodes in hulle jeugwerk, gemeentesorg, evangelisasie, ens. inlyf, terwyl hulle nog steeds ernstig bedag daarop is om tog geen Roomse praktyke na te volg nie.

Daarom het dit hoog tyd geword dat Calviniste hulle ook begin besin oor die grondbeginsels van allerlei moderne metodes van sorg, veral wanneer sulke metodes van sorg 'n sekere agressiewe neiging openbaar en sommige erkende christelike metodes verdring: soos bv. wanneer die maatskaplike werk die diakonale barmhartigheidsdiens verdring; wanneer die staatskool die gesamentlike verantwoordelikheid van die ouers en die kerk t.o.v. die opvoeding oorneem; of wanneer die welsynstaat die totale versorging van individue onderneem.

As ons nou die verskillende metodes van sorg wat deur die moderne mensdom op die spits gedryf word aan 'n deurtastende ondersoek onderwerp, dan vind ons dat hulle byna sonder uitsondering produkte is van die religie van die kommunard.

Die sentrale en alles beheersende probleem van die moderne mensheid is im. mers sy eensaamheid waarvoor hy ontvlugting soek in menslike gemeenskapsvorming. Sy drang na gemeenskap het by hom 'n obsessie geword. Om gemeenskap te smak word sy groot ideaal - en Die Gemeenskap sy afgod. Alles geskied nou in, deur 
en tot Die Gemeenskap. Alles en almal word gestel in diens van Die Gemeenskap: die wetenskap, tegniek, die psigologie, die staatsmag en masjinerie, die landbou, die nywerheid, ja selfs die oorlogstuig, want beide die afgelope wêreldoorloë vir vrede het uitgeloop op ekumeniese stigtinge, t.w. die Volkerebond en die V.V.O. Die begrippe Kommunisme, sosialisme, maatskappy, gemeenskap, komeraadskap, ens. is huishoudelike woorde in die moderne samelewing - of dit nou in die Ooste is of in die Weste, in die Noordelike halfrond of in die Suidelike.

Hierteenoor het ons gesien dat ook by die christendom die gemeenskap 'n sentrale plek inneem. Die christen bely immers:

„Ek geloof aan die gemeenskap, heilige verbintenis van wie almal saam 'n eenheid, in hul HEER één liggaam is". Boide die twee botsende elemente in die huidige kultuurkrisis streef dus na, en is gerig op, GEMEENSKAP.

Maar daar is 'n wesensverskil tussen die twee soorte van gemeenskap!

Van die gemeenskap waarna die utopis strewe sê Daniel reeds: ,hulle sal deur menslike gemeenskap onder mekaar vermeng raak, maar hulle sal nié aan mekaar vasklewe nie, net soos yster nie met klei meng nie" (Dan. 2 : 43).

Van die gemeenskap waaraan die christen glo bely ons dat hierdie heilige verbintenis "'n eenheid, in hul HEER één liggaam" is.

Hier het ons te doen met twce wesens. verskillende soorle van gemeenskap. Die. selfde weg kan nie na beide lei nie. Dieselfde metodes van sorg kan nie met hetrekking tot beide ,gemeenskappe" aan. gewend word nie, want die een is 'n ver. loëning van die ander. Anders sou daar geen hotsing en geen kultuurkrisis gewees het nie.

Wanneer die christendom dus metodes van sorg uit die ander kamp wil oorneem moet dit noodwendig op sinkretisme uitloop.

So is dit ook inderdaad, maar só onskuldig en só „efficient" skyn dié vreemde metodes van sorg te wees dat dinge soos gemeenskapsentrums, sosiale of maatskaplike werksters, gemeenskaplike eethuise, gemeenskapsorganisasie, groepwerk, gemeenskapskaste, Alkoholiste Anoniem, Tafelrondes, Rotariërs, Morele Herbewapening, staatspensioene, ens. op christelike erf soos eiendomlike erfgoed lyk, terwyl dit in werklikheid skering en inslag van die moderne antichristelike utopistiese kultuurpatroon is. Dit is by uitnemendheid die versorgingsmetodes van die beoefenaars van die religie van die kommunard.

Die Calvinis het ook behoefte aan 'n gemeenskapsentrum, maar dié het hy in die kerk; hy het ook behoefte aan ,maatskaplike werkers", maar dié het hy in die kerklike ampsdraers; aan die nagmaalstafel eet gelowiges gemeenskaplik saam; hulle kerklike organisasie is hulle gemeenskapsorganisasie; hulle eredienste; hulle groepwerk; hulle gemeentelike kas (waaronder die diakonale kas) vervul die rol van 'n gemeenskapskas, ens. ens.

Wat meer is, in die Gemeenskap van die Heiliges werk nie blote ,sosiale krag. te" soos by die religie van die kommunard nie - in die Gemeenskap van die Heiliges werk 'n meta-sosiale krag: God die Heilige Gees.

Deur die werking van die Heilige Gees vind versoening plaas tussen die hoetvaar. 
dige enkeling en God en tussen die boetvaardige enkeling en die heiliges. Dan word al die eensame enkelinge kinders van één Vader en broeders en susters in Jesus Christus.

In Sy Raad het God dit so gewil dat hierdie Versoening aan die enkeles, aan die eensames bedien sal word deur die ampsdraers in die Kerk. Hulle is die bedienaars van die Versoening. Die hele kerklike organisasie is hierop ingestel, $\mathrm{nl}$. om die Versoening in Jesus Christus te bedien om sodoende die enigste ware $\mathrm{Ge}$ meenskap tot stand te bring.

$\mathrm{Na}$ aanleiding van die voorgaande kan ons dan ook, mede op grond van wat in Ef. 4 : 11-16 staan, konkludeer dat die nougesette bediening van die versoening deur die drie kerklike ampte tesame ook in ons tyd - ja, veral in die huidige kultuur. krisis - by uitstek die metode is om die verbondsjeug te versorg.

C. N. Venter. 